\title{
Metal-ligand bond lengths and strengths: are they correlated? A detailed CSD analysis
}

\author{
Anders Nimmermark ${ }^{\mathrm{I}}$, Lars Öhrström ${ }^{*}, \mathrm{I}$ and Jan Reedijk ${ }^{\mathrm{II}}$

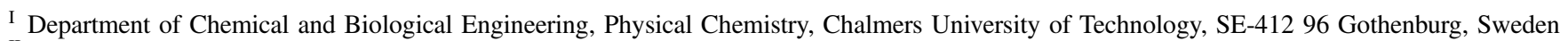

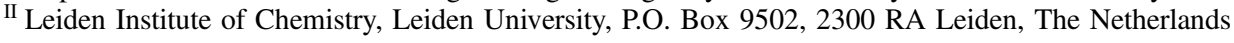

Received January 5, 2013; accepted May 28, 2013

Published online: July 1, 2013

\section{Metal-ligand bonds / Bond strength / Bond length / MOF / Coordination compounds}

\begin{abstract}
Structure data on metal-alkoxides, metal-alcohol, metal-carboxylates, metal-carboxylic acid, metal-azolate and metal-azole coordination compounds from the Cambridge Structural Database (CSD) were analysed in terms of bond lengths. In general the anionic ligands form shorter metal-ligand bonds by about $0.02-0.05 \AA$ compared to neutral ligands, a clear indication of a charge contribution to the bonding interactions. This small difference is not, however, deemed as sufficient to generate two distinct classes of metal-ligand bonding. Instead, the anionic ligands can be viewed as having "charge assisted" metalligand bonding, corresponding to the same term used for "charge-assisted hydrogen bonding".
\end{abstract}

\section{Introduction and background}

While carbon-carbon bond lengths and bond strengths in terms of bond enthalpies are well established and can be found in $1^{\text {st }}$ year university chemistry textbooks, useful and accurate data of the same type for metal-ligand bond strengths are notoriously difficult to find in the same type of literature.

In light of the recent proposition that bonds in coordination compounds can be divided into two classes based on bond strengths, namely those with neutral ligands and weak bonds, such as ammonia in the classical Werner complex $\left[\mathrm{PtCl}_{2}\left(\mathrm{NH}_{3}\right)_{2}\right]$, and those with anionic ligands and strong bonds that can also be thought of as salts, such as $\left[\mathrm{Cu}_{2}\left(\mathrm{O}_{2} \mathrm{CCH}_{3}\right)_{4}\right]$ [1], it seemed important to investigate if there is any structural evidence supporting this suggestion. This classification has especially concerned materials with metal-ligand bonding extending in 1,2 , or 3 dimensions, thus dividing these into less stable coordination polymers and highly stable metal-organic frameworks, a view contested by Robson [2].

* Correspondence author (e-mail: ohrstrom@chalmers.se) For supplementary information see online version.
Since then, the notion of a strict division has gradually disappeared as the grey zone in-between the two extremes is large, important and expanding. Thus the view has evolved that such distinction, regardless of its scientific merits, is indeed impossible to maintain for nomenclature and terminology purposes [3].

The present study will attempt to address the bond strength question by analysing in detail data from the Cambridge Structural Database, CSD [4]. In this correspondence bond energy, stability constants and bond valences will be used to assess the bond strength.

Although there seems to be no similar detailed study focusing on the metal-ligand bond, a general survey on bond lengths in coordination compounds was recently published [5].

\subsection{IUPAC recommendations}

As noted above, for terminology purposes a distinction according to charge of the ligand is not practical, and the disagreement over this issue has in fact been resolved by IUPAC. Recently provisional recommendations, defining coordination polymers as an overall substance class, coordination networks as a subclass and metal-organic frameworks as special case of coordination networks, the definition relying on structure rather than on bonding, were published [6].

\subsection{Coordination bonds and valence bond theory}

The scientific question, however, remains challenging and deserves a detailed study in order to be answered. Are carboxylate coordination entities and pyridine coordination entities indeed so different in bonding that a clear distinction can be made between them?

The argument usually put forward to support their difference is based on bond valence theory [7]. Formal bond valence values are assigned according to the valence of the atoms and the total charge of the ligand.

A metal has a valence of $+n$ and an imidazolate ligand a valence of -1 , they can thus form a bond of valence, 1 see Fig. 1. An imidazole or pyridine ligand is neutral and has thus valence zero and the total metal-ligand bond valence becomes zero [8]. 

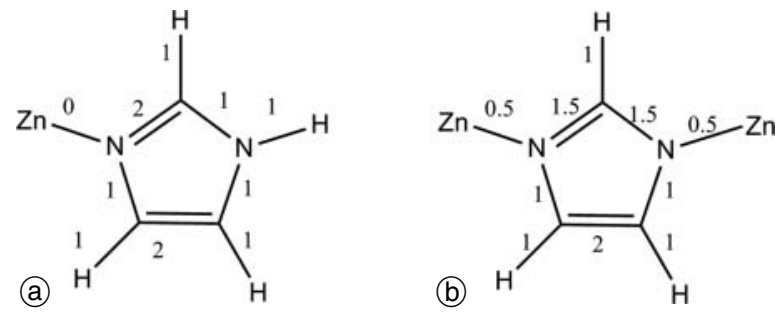

Fig. 1. Assigned formal bond valences of; (a) zinc(II)-imidazole and (b) Zn-imidazolate-Zn. Modified from Tranchemontagne et al. [8].

The same would apply to tertiary amine ligands, $\mathrm{NR}_{3}$, but the argument becomes less clear for complexes with ammines, $\mathrm{M}^{n+}-\mathrm{NH}_{3}$, as the nitrogen here is surrounded by four Lewis acids. For the fragment $\mathrm{M}^{n+}-\mathrm{NH}_{3}$ a first approximation would assign a bond valence of $3 / 4$ to all bonds. The theory, however, is usually applied on structural data and collections of bonds and bond lengths, and typically would give values closer to one for the $\mathrm{N}-\mathrm{H}$ bonds and much less to the $\mathrm{M}-\mathrm{N}$ bond.

One example is the calculation of bond valences in (dimethylsulfoxide)pentaammineruthenium(II) hexafluoridophosphate (DMSARU) where the bond valence of the $\mathrm{N}-\mathrm{H}$ bond is 0.88 and the bond $\mathrm{N}-\mathrm{Ru}$ has a bond valence of 0.36, see Fig. 2 [7]. Still the total valence sum for nitrogen is 1 . Another noteworthy item is the strength of the $\mathrm{Ru}-\mathrm{S}$ bond on which Brown comments that a bond valence close to zero $(0.22)$ not necessary means that the bond is weak.

"The metal-S bond is strictly represented by two bonds, a $\sigma$ bond directed from $\mathrm{S}^{4+}$ to the metal, and a $\pi$ bond directed from the metal to $\mathrm{S}^{4+}$. The fluxes in these two bonds almost cancel, so the net flux of the bond is small, typically less than $0.2 \mathrm{vu}$, even though the bond itself may be quite strong" [7].

The formal bond-valence method is clearly only quantitatively applicable on systems that can be described as individual ionized atoms. "One advantage of the bond valence approach is that each bond is treated as an individual and hence irregularities and distortions in the coordination environments can be taken into account" [7]. This

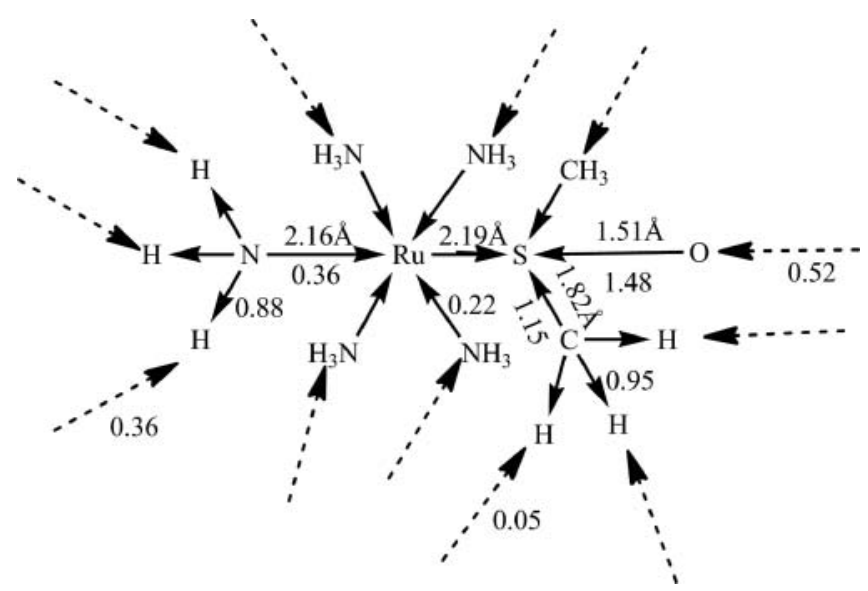

Fig. 2. Bond valences of bonds in (dimethylsulfoxide)pentaammineruthenium(II) hexafluoridophosphate (DMSARU), the bond lengths were obtained by the authors from the CSD. Picture modified from Brown [7]. points to the fact that the formal bond valence approach must be adapted through calculations of the dependencies between bond valence and bond lengths. A general and broadly accepted equation for calculating bond valences from bond lengths is:

$$
v=\mathrm{e}^{\frac{R-d}{b}}
$$

where $R$ is the experimental single bond length $d$ ist the bond distance, and $b$ the Brown Altermatt constant $b=0.37 \AA$. A bond length of $>3.5 \AA$ corresponds to a valence close to zero.

In all its simplicity the bond valence theory is quite powerful, as it is also able to include the long-range ionic effects, that are otherwise difficult to estimate without resorting to more complicated calculations, like Madelung fields etc. [7].

\subsection{Metal-ligand bond strengths}

The scientific questions, whether carboxylate coordination entities and pyridine coordination entities are different in bonding and whether the bond energies are significantly different in magnitude, will now be addressed by comparing bond lengths.

Based on the similarity of $\mathrm{Zn}-\mathrm{O}$ bond lengths and angles in $\mathrm{ZnO}$ and $\mathrm{MOF}-5$ (the three-dimensional coordination polymer $\left.\left[\mathrm{Zn}_{4} \mathrm{O}\left(\mathrm{O}_{2} \mathrm{CC}_{6} \mathrm{H}_{4} \mathrm{CO}_{2}\right)_{3}\right]\right)$ it had been suggested [1] that their bond energies would also be similar, thus giving for each $\mathrm{Zn}-\mathrm{O} 180 \mathrm{~kJ} / \mathrm{mol}$, while the $\mathrm{Cu}-\mathrm{N}$ bond in e.g. $\left[\mathrm{CuCl}_{2}\left(\mathrm{NH}_{3}\right)_{2}\right]$ was estimated to be about $90 \mathrm{~kJ} / \mathrm{mol}$ [1]. We refer here also to Rodgers and Armentrout, to illustrate the great variations observed in $\mathrm{M}-\mathrm{L}$ bond strengths [9].

These $\mathrm{Zn}-\mathrm{O}$ bond energies are sometimes compared to carbon-carbon bond energies (known to be about $350 \mathrm{~kJ} / \mathrm{mol}$ ), although it should be kept in mind that the $\mathrm{C}-\mathrm{C}$ bond energies are those of homolytic bond cleavage, and the difficulty of breaking $\mathrm{C}-\mathrm{C}$ bonds has perhaps more to do with kinetics than an inherent stability. Coordination bonds, being either based on a Lewis acid - Lewis base interaction of a localized lone electron pair, or on a non-specific electrostatic interaction, are often, but not always, kinetically more labile [10].

One can also argue using the basicity of the ligands as a parameter, the more basic the ligand, the stronger the metal-ligand bond. This would put the $\mathrm{M}-\mathrm{L}$ bond strengths in the order carboxylate $\left(\mathrm{p} K_{\mathrm{a}} \approx 5\right) \approx$ pyridine $\left(\mathrm{p} K_{\mathrm{a}}=5\right) \ll \mathrm{O}^{2-}\left(\mathrm{p} K_{\mathrm{a}} \approx 36\right)[11,12]$. Another experimental measure is based on equilibrium constants. From Stability Constants we find that the logarithm of the formation constants for $\mathrm{Cu}$ (II) with imidazoles, carboxylates and pyridines have the average values 8.5, 3.9 and 3.4, respectively [13], i.e. the value for anionic ligands fall in between the two neutral ligands. Normally, this would correspond to a reaction in which water is replaced by the ligand so the $\Delta G_{\mathrm{r}}^{\circ}$ values we can calculate from these data are differences in bond energy rather than absolute values. We also note the large width and variation in these values (see Table S.1) giving for example a range of $\Delta G_{\mathrm{r}}^{\circ}$ values for the imidazoles from -26 to $-35 \mathrm{~kJ} / \mathrm{mol}$. 


$$
\begin{aligned}
& \begin{array}{lr}
\mathrm{R}_{1}^{\mathrm{M}} & \mathrm{M}^{\odot} \mathrm{H} \\
\mathrm{R}^{-\mathrm{O}^{\odot}}
\end{array}
\end{aligned}
$$

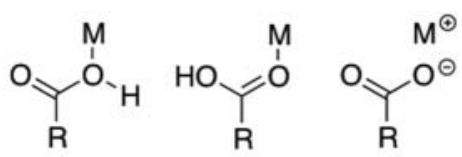

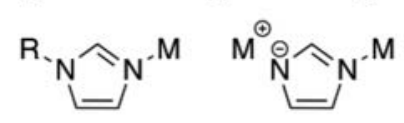

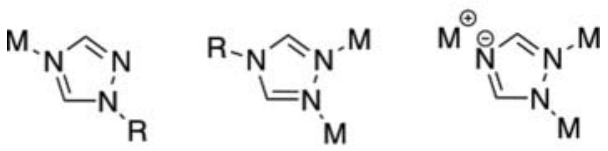

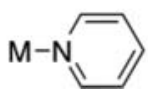

Fig. 3. Systems searched in the Cambridge Structural Database (CSD). $\mathrm{M}=\mathrm{Co}, \mathrm{Ni}, \mathrm{Cu}, \mathrm{Zn}$. For comparison we have also searched pyridine systems although in this case there is no appropriate anion to compare with. Note that formal charges are emphasized in this figure, the actual searching was performed with a formal bond between $\mathrm{M}^{+}$and $\mathrm{L}^{-}$. ( $\mathrm{R}=\mathrm{H}$ or organic fragment). Only the most frequently occurring structures of the triazole complexes were considered.

Quantum chemistry can also be used, and especially gas-phase calculations are known to be accurate, albeit with disputed relevance for solution and solid state chemistry. Thus Ducéré et al. calculated the $\mathrm{Cu}-\mathrm{N}$ bond energy by the dissociation of $\left[\mathrm{Cu}\left(\mathrm{NH}_{3}\right)_{4}\right]^{2+}$ to $\left[\mathrm{Cu}\left(\mathrm{NH}_{3}\right)_{3}\right]^{2+}$ and $\mathrm{NH}_{3}$ to $160 \mathrm{~kJ} / \mathrm{mol}$ both using a B3LYP DFT method and MP2 perturbation theory [14].

\subsection{Metal-ligand bond strengths and bond lengths}

Shorter bond lengths are generally seen as a sign of a stronger bond, but comparisons for dissimilar systems must be made carefully. Tilset and co-workers point out in their theoretical study of MOF-5 that $\mathrm{ZnO}$ may be different in terms of bonding, even though the bond lengths and angles are similar as "... significant differences may arise from the isolated nature of the oxide nodes ..." compared to "the organic linker" [15].

In this study we have investigated bond lengths of metal-alkoxides, metal-alcohol, metal-carboxylates, metal-carboxylic acid, metal-imidazolates, metal-imidazole, metaltriazoles and metal-pyridine coordination compounds from the Cambridge Structural Database (CSD) [4], with the aim to find out whether there are any significant structural indications to classify these compounds into two distinct species. The schematic structures are given in Fig. 3. In the analysis we found it hard to eliminate possible effects of $\mathrm{H}$ bond donor/acceptor properties of the O-donor ligands but that this was easier for the azole ligands (vide infra).

\subsection{Details of the CSD searches}

In all runs the Conquest software (version 1.14) was used with the restrictions that all retrieved structures would have $R$ values $<10 \%$ and be error and disorder free. No powder structures were included.

\section{Results and discussion}

We will first discuss the alcohol and alkoxide systems, as most data are available for these groups of compounds. Subsequently the carboxylate and carboxylic acid complexes will be discussed, then the azole and azolate structures and finally we will compare both systems to pyridines, where there is no corresponding anionic coordination possible.

The data needs careful analysis and discussions, as complications may occur, e.g. by the valence state of the metal and by the variations in coordination number. So, for cobalt we have both $\mathrm{Co}$ (II) and $\mathrm{Co}$ (III) compounds, for copper we have $\mathrm{Cu}(\mathrm{I})$ and $\mathrm{Cu}$ (II) and for all metals the possibility of different coordination numbers should be considered, especially for octahedral-based $\mathrm{Cu}$ (II), where almost always two long and four shorter $\mathrm{Cu}-\mathrm{L}$ bonds are found. Finally, we will only present data for systems yielding a sufficient number of hits $(>60)$.

\subsection{Metal alcohol and alkoxide systems}

For these compounds only copper gave a sufficient number of hits for both protonation states and the results are presented in Fig. 4; (1056 hits for $\mathrm{Cu}-\mathrm{OH}$ and 146 hits for $\mathrm{Cu}-\mathrm{O}$ ). It is not possible to search explicitly for oxidation states in the CSD, except for text strings in the names such as "copper(II)". This information is not always given, but it appears that the data in Fig. 4 is composed of at least 98\% of copper(II) compounds, see Figure S.1. The complete data collection is found in Table S.2.

We first of all see that neutral alcohols can act as two kinds of ligands: with short bonds and long bonds. The double hump shape of the alcohol complexes thus clearly reflects the Jahn-Teller distortion of $\mathrm{Cu}$ (II), and certainly is not a difference between $\mathrm{Cu}(\mathrm{I})$ and $\mathrm{Cu}$ (II). For the alkoxides, we only find the short bonds as one would expect from a charge point of view. The absence of a Jahn-Teller hump for the alkoxides appears to arise from the fact that

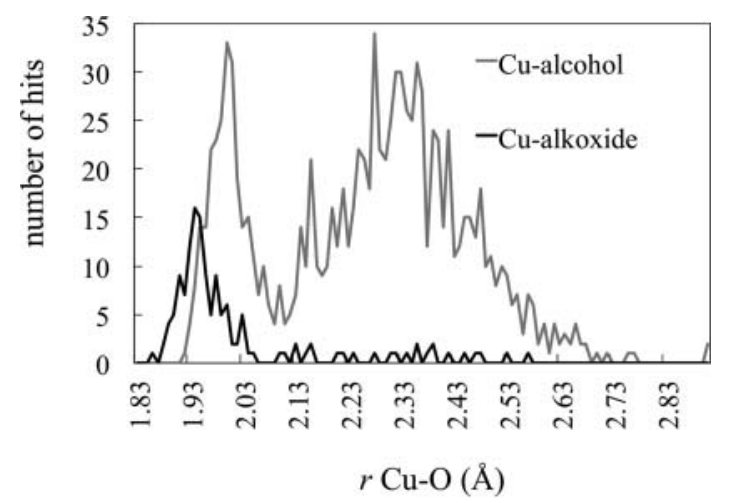

Fig. 4. CSD search for copper-alcohol and copper-alkoxide structures, all coordination numbers used and more than $98 \%$ of the compounds are $\mathrm{Cu}(\mathrm{II})$. Throughout the article black and solid unfilled graphs correspond to anionic ligands and grey and or dashed graphs to neutral ligands. 
these complexes are always having the OR ligand in the equatorial plane, or are often just square planar four-coordinated. Thus these $\mathrm{Cu}-\mathrm{OR}$ bonds are not subjected to any elongation.

In general lower coordination numbers give slightly shorter bond lengths (quite in agreement with bond valence theory, where this observation is sometimes even used to calculate oxidation states [16]), but not enough to make a difference on the scale we are interested in. Comparing $\mathrm{Cu}$-alcohol complexes with coordination numbers 5 and 6 it is for example seen that the shortest distances stay the same, although a slight shift to shorter bond lengths is observed for the longer (Jahn-Teller distorted) $\mathrm{Cu}-\mathrm{O}$ bonds (details are in Table S.2).

The difference between the alkoxides and the alcohol complexes, measured as the distance between the two peaks at shorter bond lengths, is $1.99-1.94 \AA$, thus $0.05 \AA$. Some of this difference may be due to higher coordination numbers of compounds with the alcohols. Nevertheless it seems fair to say that the maximum bond length difference between $\mathrm{Cu}-\mathrm{OR}$ and $\mathrm{Cu}-\mathrm{OH}-\mathrm{R}$ is about $2.5 \%$.

A typical example (for details see Table S.3) for the neutral alcohols is octahedral tris(1,2-ethanediol)copper(II) sulfate (ETDOCU01) [17] with $\mathrm{Cu}-\mathrm{O}$ bond lengths 1.956 , $1.964,1.998,2.000,2.312$, and $2.33 \AA$ with average for the four short bonds at $1.98 \AA$. Two alkoxides examples are: bis(dimethylamino-2-methyl-2-propanolato)copper(II) (BESHUD) [18] with the two $\mathrm{Cu}-\mathrm{O}$ bond lengths at $1.864 \AA$ and bis(9-(2-pyridyl)fluoren-9-olato-N,O)copper(II) methanol solvate (LIVFAY) [19] with the two $\mathrm{Cu}-\mathrm{O}$ bond lengths at 1.911 and $1.912 \AA$. These shorter bonds are to be ascribed partly to the fact that the alcoholate is part of a $\mathrm{N}$-containing chelating ligand and that in this case the coordination number is 4 , as there are no axial ligands present. No cases are known with only 4 alcohols coordinated in a square planar structure.

While we are convinced that most of the structures retrieved have the correct protonation state of the alcohol/ alkoxide, the fact that the protons are difficult to locate on the electron density map implies that in some cases there is doubt whether or not the hydrogens have been correctly placed in the structure.

Another factor we have not taken into account is hydrogen bonding, or secondary coordination, not explicitly indicated in the CSD. An alkoxide may accept a strong hydrogen bond from a proton donor, or have a weak interaction with another Lewis acid not formally considered as a bond. On the other hand a coordinated alcohol can be a strong hydrogen-bond donor to an adjacent base, thereby weakening the $\mathrm{M}-\mathrm{O}$ bond, and this is not taken into account either.

\subsection{Metal carboxylic acid and carboxylate systems}

In this case only few data are available on the protonated systems. What we can clearly state is that for copper, where we have at least 7 structures fulfilling all our quality criteria, the shortest $\mathrm{Cu}-\mathrm{O}(\mathrm{H})$ bond is $1.93 \AA$ (bis $(\mu$-aspartame)tetrakis(aspartame)diaquatricopper(II) pentahydrate, MAZSAI) [20], which is actually shorter than the peak copper-carboxylate distance, $1.95 \AA$ (Fig. S.2). However,

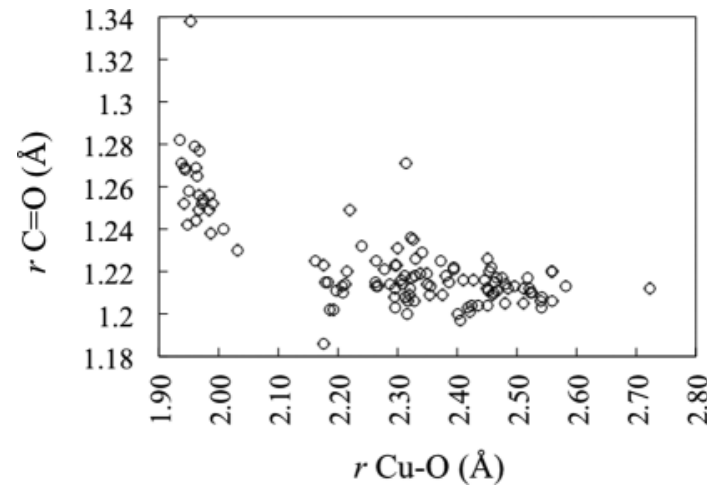

Fig. 5. $\mathrm{Cu}-\mathrm{O}$ distances ( $x$-axis) for keto-coordinating copper(II) neutral carboxylic acid complexes versus $\mathrm{C}=\mathrm{O}$ bond lengths ( $y$-axis). "Normal" $\mathrm{C}=\mathrm{O}$ and $\mathrm{C}-\mathrm{O}$ distances are 1.20 and $1.43 \AA$ respectively and the most frequent $\mathrm{Cu}-\mathrm{O}$ bond length in carboxylate complexes is $1.95 \AA$ (Fig. S.2).

this is probably a case of misplaced protons, as more logical hydrogen bonding is achieved with the longer $\mathrm{Cu}-\mathrm{O}$ oxygen protonated giving the actual $\mathrm{Cu}-\mathrm{OHCOR}$ as $2.521 \AA$, illustrating the problem of uncritically trusting the database. The longest $\mathrm{Cu}-\mathrm{O}(\mathrm{H}), 2.683 \AA$ for catena-(bis $(\mu$ D-Hydrogen malato)-copper(II) dihydrate, CUHMAM01 [21], is best seen as a semi-coordination bond, but it is notable that the keto oxygen of the $\mathrm{COOH}$ group, that is also apically coordinated and subject to Jahn-Teller distortion, see Fig. 5, has a shorter $\mathrm{Cu}-\mathrm{O}$ bond at $2.338 \AA$.

It is not surprising that only a handful of $\mathrm{OH}$-coordinated carboxylic acid complex are found, as the keto-oxygen is the more basic site. Searches of keto-coordinated carboxylic acid complexes consequently give higher counts, but also here there is some uncertainty as to the protonation state. For the unambiguous $\mathrm{C}=\mathrm{O}$ bonds $(1.20-1.25 \AA)$ the same general picture as in Fig. 2 emerges for the $\mathrm{Cu}-\mathrm{O}$ bonds $(x$ axis), a first peak at $1.99 \AA$, followed by a broader hump at 2.3-2.6 $\AA$ representing the Jahn-Teller distortion, see Fig. 5. The smaller concentration of hits at $2.2 \AA$ represents the apically coordinated keto groups in the distinct class of $\mathrm{Cu}(\mathrm{II})$ paddle wheel complexes.

Between the carboxylate- and keto-coordination there is thus a difference of about $1.99-1.95 \AA=0.04 \AA$, the same order as the for alkoxide-alcohol systems. However, it should be noted that we are comparing oxygens with different hybridization and bond distances to the closest carbon atom. For example, longer $\mathrm{C}=\mathrm{O}$ bonds may indicate some degree of back-bonding. The complete data collection is found in Table S.4.

\subsection{Metal imidazole and imidazolate systems}

The imidazolate systems have a great advantage in that there is no possible protonation state ambiguity for the $\mathrm{N}$-substituted metal-imidazole- $\mathrm{R}$ compounds, and as the $\mathrm{N}$ has only one directed lone pair, therefore also hydrogen bonding effects are hardly present. For four-coordinated zinc we found a good number of data in the CSD which are plotted in Fig. 6. Total number of hits are for $\mathrm{Zn}$-Him $=318, \mathrm{Zn}-\mathrm{Rim}=656$, and $\mathrm{Zn}-\mathrm{im}-\mathrm{Zn}=60$. The complete data collection is found in Table S.5. 


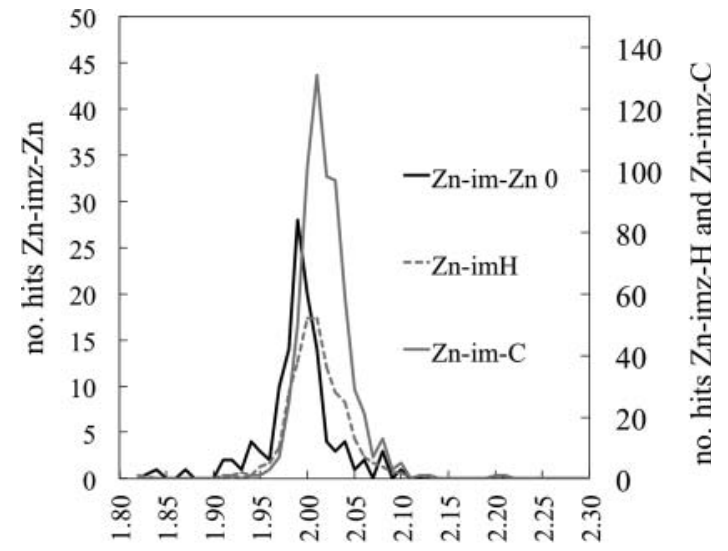

$\mathrm{r} \mathrm{Zn}-\mathrm{N}(\AA)$

Fig. 6. $\mathrm{Zn}-\mathrm{N}$ distances for four-coordinated zinc imidazole (left $y$-axis) and imidazolates (right $y$-axis).

First we note that there is no significant difference between the protonated imidazole and the imidazole substituted with a carbon (dashed grey and grey curves). For the imidazolates that bridge between two metals, there are two (in some cases slightly different) $\mathrm{Zn}-\mathrm{N}$ distances for each structure, but these have the same profile and have been added together in Fig. 6 (number of hits plotted on the left side $y$-axis).

The imidazolate compounds have a small, but still significant shift towards shorter $\mathrm{Zn}-\mathrm{N}$ bonds, peaking at $1.99 \AA$ compared to 2.01 for both the $\mathrm{Zn}-\mathrm{im}-\mathrm{H}$ and $\mathrm{Zn}-\mathrm{im}-\mathrm{C}$ structures, i.e. a $1 \%$ shortening. Compared to the alkoxide copper compounds this is about half the difference, but as there are two $\mathrm{Zn}-\mathrm{N}$ bonds in each of such structures ("sharing" the -1 charge or valence), this makes sense and we can conclude that the effect is of about the same size.

For the imidazole and imidazolate systems, we can calculate bond valence with the help of equation 1 . A bond length of $1.99 \AA$ corresponds to a bond valence of 0.548 and $2.01 \AA$ to a bond valence of 0.519 . This very small difference based on bond lengths is far from the bond valence difference of 0.5 proposed by the formal bond valence approach.

Another noticeable difference is that the distribution of values is narrower for the imidazolates (always equatorial ligands) and that the imidazoles have pronounced asymmetry with a clear "drag" towards longer distances (the axial ligands).

\subsection{Triazole systems}

Triazole compounds are also relevant to compare with and rather numerous. For the triazoles with one metal ion attached and an R group the charge is unequivocally neutral and for triazolates with three metal ions bound the charge of the ligand is minus one. For the ligands bridging two metals there may be some ambiguity, however, which should be kept in mind when analysing the triazole and triazolate data with copper. It was this metal that yielded the largest number of data and these are shown in Fig. 7.

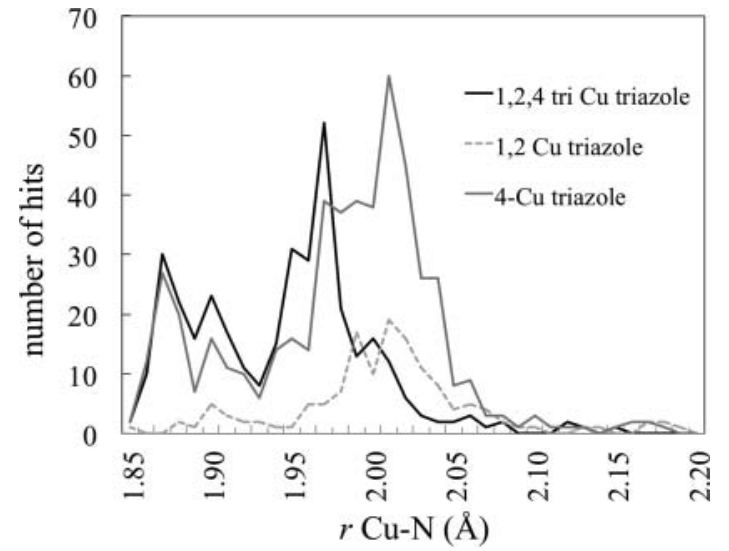

Fig. 7. $\mathrm{Cu}-\mathrm{N}$ distances of copper triazole compounds for mono, di and tri coordinated triazole.

For these compounds, which have similar structures as the imidazoles when coordinated to $\mathrm{Cu}$, the picture is more complex. This is partly due to that we now, in contrast to the alkoxides and alcohols compounds in Fig. 4, have a large number of $\mathrm{Cu}(\mathrm{I})$ complexes present. Thus the peaks at $1.87 \AA$ correspond to three-coordinating $\mathrm{Cu}(\mathrm{I})$ (and a few three coordinated $\mathrm{Cu}(\mathrm{II})$ ) and here there is no difference between charged and uncharged ligands. For $\mathrm{Cu}$ (II) and higher coordination numbers it is, however, evident that the charged ligands tend towards shorter distances, $2.01 \AA$ versus $1.97 \AA$, the difference thus being of the same order, $0.04 \AA$, as observed for $\mathrm{Cu}(\mathrm{II})$ with alkoxides. An example is the compound HOXLUB [22] where 4 triazoles are coordinated to $\mathrm{Cu}$ (II) in an equatorial way, with $\mathrm{Cu}-\mathrm{N}$ distances of $1.974-2.008 \AA$. For anionic triazolates the $\mathrm{Cu}-\mathrm{N}$ distances are in the 1.98-2.01 $\AA$ range for square-planar $\mathrm{Cu}(\mathrm{II})$, again shorter than the neutral form. Complete data are found in Table S.6.

\subsection{Comparison to pyridine systems}

The pyridines have no suitable anion to compare with, instead we wanted to see the influence of two different neutral aromatic ligands binding with nitrogen: pyridine and neutral imidazole, and we also wanted to compare

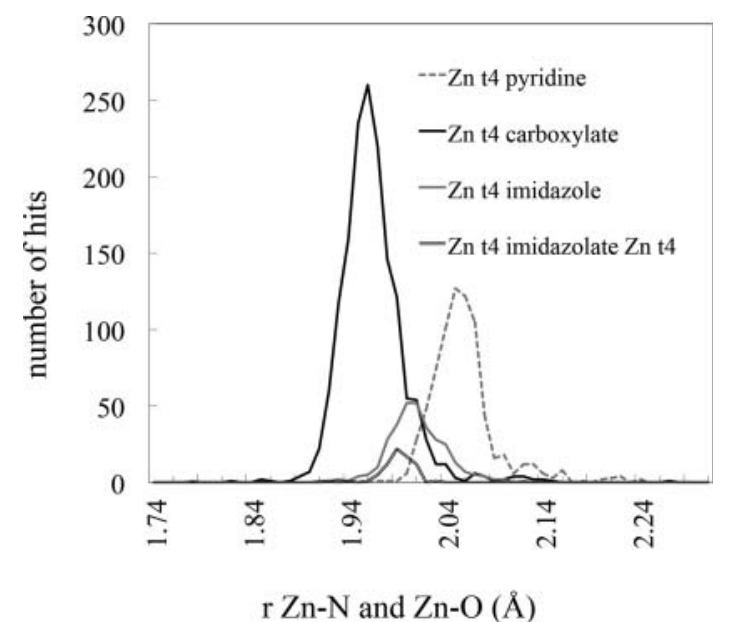

Fig. 8. $\mathrm{Zn}-\mathrm{N}$ and $\mathrm{Zn}-\mathrm{O}$ distances for four-coordinate $\mathrm{Zn}$-imidazole, $\mathrm{Zn}$-pyridine and $\mathrm{Zn}$-carboxylate compounds from the CSD. 
these to the imidazolates and carboxylates. In Fig. 8 we have plotted the $\mathrm{Zn}-\mathrm{N}$ distances for four-coordinated $\mathrm{Zn}$ (II) for both pyridine and imidazole, as well as for imidazolates and $\mathrm{Zn}-\mathrm{O}$ for carboxylates. The number of hits was 752 for pyridine, 1549 for carboxylates, 318 for imidazoles and 60 for the imidazolates.

First we note that the carboxylate distances are the shortest, $1.96 \AA$ compared to 1.99 for the imidazolates, but considering that the covalent radius of nitrogen is $0.05 \AA$ longer than for oxygen $(0.71 \AA$ versus $0.66 \AA)$ this difference is hardly significant. More interesting, and more relevant for the aim of this study, is the pronounced difference between the most probable bond distances for pyridines and imidazoles: $2.05-2.01=0.04 \AA$, i.e. of the same order as observed between ligands with similar looking anions and neutral forms.

The fact that the pyridine group is slightly more sterically demanding may perhaps be the simplest explanation for this small difference, and could suggest that steric bulk can give effects of the same order of magnitude as a neutral versus a charged ligand. Moreover, we cannot completely rule out that the difference between carboxylate and pyridine, $0.09 \AA$, is the product of a similar steric effect. As can also be clearly seen, the difference between pyridine and imidazole complexes is greater than that between imidazoles and imidazolates.

\subsection{Correlation of bond strengths and lengths}

Apart from bond valence calculations another way to correlate bond lengths and bond strengths is to use the harmonic oscillator approximation for a single bond vibration, although relative numbers will be hard to extract this way. One also has to assume that both bonds are on the same potential surface, which might not be true.

Nevertheless, as the increase in potential energy in this approximation is proportional to the square of the distance difference between the equilibrium and an extended bond, the important conclusion is that a small change in length will be magnified in terms of strength, thus a $2.5 \%$ bond length increase could indicate a much larger decrease in bond energy.

Two other simple models can also be used where we can easily get estimates of the absolute value of the bond

Table 1. The absolute interaction energies and the energy change if we increase the bond length $0.05 \AA$ for some model compounds $(\mathrm{kJ} / \mathrm{mol})$ calculated by the charge-dipole and Coulombic interaction (assuming a charge of +1 and -1 ). In the calculations $r$ corresponds to the most probable bond length for each class as reported above.

\begin{tabular}{lcccc}
\hline & \multicolumn{2}{c}{ at $r(\mathrm{~kJ} / \mathrm{mol})$} & \multicolumn{2}{c}{ at $r+0.05 \AA(\mathrm{kJ} / \mathrm{mol})$} \\
& $E_{\text {dipole }}$ & $E_{\text {coul }}$ & $\begin{array}{l}\Delta E_{\text {dipole }} \\
(\% \text { diff })\end{array}$ & $\begin{array}{l}\Delta E_{\text {coul }} \\
(\% \text { diff })\end{array}$ \\
\hline $\begin{array}{l}\text { imidazole }^{a} \\
\begin{array}{l}\text { imidazolate } \\
\text { pyridine }\end{array}\end{array}$ & 283 & & $-14(-5 \%)$ & \\
$\begin{array}{l}\text { benzoic acid }^{a} \\
\text { benzoate }\end{array}$ & 166 & 691 & & $-17(-2.5 \%)$ \\
\hline
\end{tabular}

a: Dipole moments from: Handbook of Chemistry \& Physics [23]. energy, the charge-dipole interaction and the ionic interaction. Assuming a net charge of +1 on the metal and using either the measured dipole moment of simple model ligands or a charge of -1 , we can calculate the absolute interaction energy and the change if we increase the bond length. For a distance difference of $0.05 \AA$ such data are presented in Table 1.

We note first that the charge-dipole estimates come closer to the expected metal-ligand bond energies than the charge-charge model that gives very high values indeed. This does not mean the former is necessarily a better description, but just that for the Coulombic interaction we need at least to include some repulsion between ligands to make reasonable bond energy estimates. The changes on extending the bonds $0.05 \AA$ are not dramatically different, however, and amounts to about a $5 \%$ loss of bond energy for the charge-dipole model and $2.5 \%$ for the ionic model, the difference being consistent with their different dependencies on $r$.

While this may not sound dramatic, we should bear in mind that in chemical reactions bonds are both broken and formed and it is the bond energy difference that will ultimately affect the thermodynamic outcome.

\section{Conclusions}

We observe a decrease in bond length of $0.02-0.05 \AA$ when a neutral ligand binding with $\mathrm{N}$ or $\mathrm{O}$ becomes charged minus one, the smaller values corresponding to the Zn-imidazolates. A difference of the same order of magnitude can be observed also between neutral pyridine and neutral imidazole ligands and in that particular case the difference may be attributed to steric effects.

The absolute effect of a difference of this order is hard to estimate, but it seems that a significant increase in bond energy is present for the charged systems and that this difference may play a role in the overall stability of the materials.

There are no clear indications, however, that any fundamental differences between a metal-carboxylate and a metal-pyridine bond exist, that would merit their division into two different classes, "salts" and "coordination compounds", respectively. Instead, anionic ligands can probably better be thought of as having an extra "charge assisted" component, just as has been coined in crystal engineering for "charge assisted hydrogen bonds" [24, 25].

Acknowledgements. JR and LÖ thank IUPAC for providing funds for the project Coordination polymers and metal organic frameworks: terminology and nomenclature guidelines, and all the group members for fruitful and constructive discussions. We also thank the Swedish Chemical Society for providing additional funds for the 2012 Trends in Inorganic Chemistry meeting on Metal-Organic Frameworks, Coordination Polymers and Zeolites in Stockholm. AN and LÖ thank the Swedish Research Council for support.

\section{References}

[1] O. M. Yaghi, M. O'Keeffe, N. W. Ockwig, H. K. Chae, M. Eddaoudi, J. Kim, Reticular synthesis and the design of new materials. Nature 2003, 423, 705-714. 
[2] R. Robson, Design and its limitations in the construction of biand poly-nuclear coordination complexes and coordination polymers (aka MOFs): a personal view. Dalton T 2008, 5113-5131.

[3] S. R. Batten, N. R. Champness, X. M. Chen, J. Garcia-Martinez, S. Kitagawa, L. Öhrström, M. O'Keeffe, M. P. Suh, J. Reedijk, Coordination polymers, metal-organic frameworks and the need for terminology guidelines. Crystengcomm 2012, 14, 30013004.

[4] F. H. Allen, The Cambridge Structural Database: a quarter of a million crystal structures and rising. Acta Crystallogr. Sect. B. 2002, 58, 380-388.

[5] G. Kuppuraj, M. Dudev, C. Lim, Factors Governing Metal-Ligand Distances and Coordination Geometries of Metal Complexes. J. Phys. Chem. B 2009, 113, 2952-2960.

[6] S. R. Batten, N. R. Champness, X. M. Chen, J. Garcia-Martinez, S. Kitagawa, L. Öhrström, M. O'Keeffe, M. P. Suh, J. Reedijk, Terminology of Metal-Organic Frameworks and Coordination Polymers (IUPAC recommendations 2012) Pure and Appl. Chem. in press 2013.

[7] I. D. Brown, The chemical bond in inorganic chemistry: the bond valence model. Oxford University Press: Oxford; New York, 2002.

[8] D. J. Tranchemontagne, J. L. Mendoza-Cortes, M. O’Keeffe, O. M. Yaghi, Secondary building units, nets and bonding in the chemistry of metal-organic frameworks. Chem. Soc. Rev. 2009, $38,1257-1283$.

[9] M. T. Rodgers, P. B. Armentrout, Bond strengths overviews. Mass Spectrom. Rev. 2000, 19, 215-247.

[10] H. Taube, Rates and mechanisms of substitution in inorganic complexes in solution. Chem. Rev. 1952, 50, 69-78.

[11] J. Clayden, N. Greeves, S. Warren, P. Wothers, Organic Chemistry. Oxford University Press: Oxford, 2000.

[12] G. Wulfsberg, Inorganic chemistry. University Science Books: Sausalito, Calif., 2000.

[13] A. E. Martell, R. M. Smith, Critical Stability Constants. Plenum Press: New York, 1982; Vol. 5, First Supplement.

[14] J. M. Ducéré, A. Goursot, D. Berthomieu, Comparative Density Functional Theory Study of the Binding of Ligands to $\mathrm{Cu}^{+}$and $\mathrm{Cu}^{2+}$ : Influence of the Coordination and Oxidation State. J. Phys. Chem. A. 2005, 109, 400-408.

[15] L.-M. Yang, P. Vajeeston, P. Ravindran, H. Fjellvåg, M. Tilset, Theoretical Investigations on the Chemical Bonding, Electronic
Structure, and Optical Properties of the Metal-Organic Framework MOF-5. Inorg. Chem. 2010, 49, 10283-10290.

[16] G. J. Palenik, Bond valence sums in coordination chemistry using oxidation state independent $R(0)$ values. Inorg Chem 1997, 36, 122.

[17] K. L. Zhong, Bis(1,10-phenanthroline-kappa N-2,N')(sulfatoO)copper(II) ethane-1,2-diol monosolvate. Acta Crystallogr. Sect. 2011, 67, M1215-6.

[18] J. W. Park, H. S. Jang, M. Kim, K. Sung, S. S. Lee, T. M. Chung, S. Koo, C. G. Kim, Y. Kim, Synthesis of $\mathrm{Cu}(\mathrm{II})$ aminoalkoxide complexes and their unusual thermolysis to $\mathrm{Cu}(0)$. Inorg. Chem. Commun. 2004, 7, 463-466.

[19] G. M. Lobmaier, G. D. Frey, R. D. Dewhurst, E. Herdtweck, W. A. Herrmann, Rhenium, palladium, and copper pyridylalkoxide complexes: Synthesis, structural characterization, and catalytic application in epoxidation reactions. Organometallics 2007, 26, 6290-6299.

[20] M. Cavicchioli, A. C. Massabni, A. M. D. Ferreira, E. E. Castellano, M. S. Crespi, Synthesis, structure and redox properties of an unexpected trinuclear copper(II) complex with aspartame: $\left[\mathrm{Cu}(\mathrm{apm})(2) \mathrm{Cu}\left(\mathrm{mu}-\mathrm{N}, \mathrm{O}: \mathrm{O}^{\prime}\right.\right.$-apm)(2)(H2O) $\left.\mathrm{Cu}(\mathrm{apm})(2)(\mathrm{H} 2 \mathrm{O})\right]$ center dot 5H(2)O. Inorg. Chim. Acta 2005, 358, 4431-4436.

[21] R. V. Gudavarthy, N. Burla, E. A. Kulp, S. J. Limmer, E. Sinn, J. A. Switzer, Epitaxial electrodeposition of chiral $\mathrm{CuO}$ films from copper(II) complexes of malic acid on $\mathrm{Cu}(111)$ and $\mathrm{Cu}(110)$ single crystals. J. Mater. Chem. 2011, 21, 6209-6216.

[22] G. A. van Albada, R. C. Guijt, J. G. Haasnoot, M. Lutz, A. L. Spek, J. Reedijk, Two examples of novel and unusual doublelayered, two-dimensional $\mathrm{Cu}^{\mathrm{II}}$ compounds with bridging 1,3bis(1,2,4-triazol-1-yl)propane. Eur. J. Inorg. Chem. 2000, 121126.

[23] CRC Handbook of Chemistry and Physics. 63 ed.; CRC Press, Inc.: Boca Raton, FL, 1982.

[24] D. Braga, F. Grepioni, Intermolecular interactions in nonorganic crystal engineering. Acc. Chem. Res. 2000, 33, 601-608.

[25] S. U. Son, J. A. Reingold, G. B. Carpenter, P. T. Czech, D. A. Sweigart, Charge-Assisted Hydrogen Bonding and Other Noncovalent Interactions in the Self-Assembly of the Organometallic Building Block $\left[\left(\eta^{6} \text {-hydroquinone }\right) \operatorname{Rh}\left(\mathrm{P}(\mathrm{OPh})^{3}\right)^{2}\right]^{+}$with a Range of Counteranions. Organometallics 2006, 25, 52765285 . 